\title{
Vagal Preganglionic Neurons Innervating the Different Gastric Regions in the Japanese Quail (Coturnix japonica)
}

\author{
By \\ Yasushi IIZUKA and Shoei SUGITA \\ Laboratory of Function and Morphology, Department of Animal Science, Faculty of Agriculture, Utsunomiya
}

University, 350 Mine-machi, Utsunomiya-shi, Tochigi 321, Japan

- Received for Publication, March 25, 1995-

\begin{abstract}
Key Words: Quail, Proventriculus, Gizzard, Dorsal motor nucleus of the vagus nerve, Horseradish peroxidase, Gastric innervation

Summary: The cytoarchitecture and distribution patterns of the vagal preganglionic neurons within the dorsal motor nucleus of the vagus nerve (DMNX) innervating the proventriculus and the gizzard of the Japanese quail were examined by Nissl staining and the horseradish peroxidase (HRP) method. A $30 \%$ solution of HRP was injected into nine different gastric regions: the ventral and dorsal parts of the proventriculus, the caudodorsal and cranioventral thick muscles, the craniodorsal and caudoventral thin muscles, and the pylorus, and the ventral and dorsal tendons of the gizzard. Nissl preparations showed that the DMNX is composed of two cell groups, the dorsal magnocellular and mediocellular subnucleus (Xd) and the ventral parvicellular subnucleus (Xv). After injection of HRP into the ventral and dorsal parts of the proventriculus, HRP-labeled cells were predominantly observed in the left and right DMNX, respectively. The rostrocaudal distribution patterns of HRP-labeled cells in the $\mathrm{Xd}$ and $\mathrm{Xv}$ were symmetric on the left and right sides. The distribution patterns of labeled cells following the injection of HRP into each region of the gizzard showed that there was very little difference in the number of neurons between the left and right DMNX, and no topographic localization was found in the Xd and Xv. The vagal preganglionic neurons projecting to the gizzard lay more caudal than the ones for the proventriculus. This study suggested topographic localization in the distribution patterns of the vagal preganglionic neurons innervating the proventriculus and the gizzard.
\end{abstract}

The avian stomach is differentiated into the proventriculus (glandular stomach) and the gizzard (muscular stomach), corresponding to the fundus and the pylorus of the mammalian stomach, respectively. The gizzard, which is composed of two pairs of opposing muscles termed the caudodorsal and cranioventral thick muscles, and the craniodorsal and caudoventral thin muscles (Dziuk \& Duke, 1972), is connected to the duodenum via the pylorus. The proventriculus is known to be the site of gastric secretion and the primary organ of chemical digestion, while the function of the gizzard is mechanical digestion and grinding of food (Duke, 1986). Physiological studies (Duke, 1982, 1992; Duke \& Kostuch, 1975; Dziuk \& Duke, 1972; Chaplin \& Duke, 1983, 1990) have shown that the gastric motility coordinating the avian digestive function begins with contraction of the pair of thin muscles of the gizzard. Then, the pair of thick muscles of the gizzard start contraction following duodenal peristalsis, and finally the proventriculus contracts.

It is widely accepted that the primary motor nerve innervating the avian stomach originates from the dorsal motor nucleus of the vagus nerve in the medulla oblongata (Bennet, 1974). Neuroanatomical studies in mammals (Takayama et al., 1982; Pagani et al., 1983; Okumura \& Namiki, 1990) have indicated that the distribution pattern of the vagal preganglionic neurons reflects the innervation of the different gastric regions. There are, however, few studies about the vagal innervation system of the avian stomach. Topographic representation of visceral target organs within the dorsal motor nucleus of the vagus nerve (DMNX) has been examined by the retrograde degeneration method in the chicken (Watanabe, 1968) and by the retrograde tracer method in the pigeon (Katz \& Karten, 1985). Unfortunately, these studies examined the distribution pattern of the vagal preganglionic neurons innervating the stomach, giving little information about the 
topographic relationship between the vagal nucleus and the partial gastric regions.

We performed the present study to determine the projections of the preganglionic neuronal group in the dorsal motor nucleus of the vagus nerve to the nine different gastric regions, including the proventriculus and gizzard, in the Japanese quail.

\section{Materials and Methods}

Forty-six Japanese quails (Coturnix japonica) of both sexes, weighing $100-140 \mathrm{~g}$, were used in the study. Forty-one of them were used for the horseradish peroxidase (HRP) method and the rest were used for Nissl preparations.

\section{(a) Nissl preparations}

Animals were deeply anesthetized with sodium pentobarbital and bled by cutting the heart. The dorsal part of the brain was exposed by removing the temporal bone and then immersing it in a $10 \%$ formalin solution in phosphate buffer. After a week, the brain was removed from the skull and immersed in a $20 \%$ sucrose phosphate buffer solution for one night, and was them cut into serial coronal sections of $60 \mu \mathrm{m}$ with a freezing microtome. The sections were stained with cresyl violet. The diameters of 100 cells within nucleolus were randomly collected, in each subnucleus of the DMNX, were measured.

\section{(b) HRP method}

Animals were anesthetized with sodium pentobarbital $(1.3 \mathrm{mg} / 30 \mathrm{~g}$ of body weight $)$ and a ventral incision was made in the abdomen to expose the stomach. A $30 \%$ solution of HRP (Sigma type IV) in physiological saline $(5 \mu \mathrm{l})$ was injected into seven different gastric regions (one injection site for each animal): the ventral (VP) and dorsal (DP) parts of the proventriculus, the caudodorsal (CaTk) and cranioventral (CrTk) thick muscles, the craniodorsal $(\mathrm{CrTn})$ and caudoventral $(\mathrm{CaTn})$ thin muscles, and the pylorus (PY) of the gizzard (Fig. 1). Five animals were used for each experiment. As an additional experiment, HRP was injected into the ventral (VT) and dorsal (DT) tendons of the gizzard (Fig. 1) using six animals (three for each injection site). After 24 hours, the birds were deeply anesthetized again and perfused transcardially with $200 \mathrm{ml}$ of Ringer's solution at $40^{\circ} \mathrm{C}$, followed by $500 \mathrm{ml}$ of $1 \%$ paraformaldehyde and $1.25 \%$ glutaraldehyde in $0.1 \mathrm{M}$ phosphate buffer ( $\mathrm{pH} 7.4$ ), and finally with $10 \%$ sucrose in the same buffer. The brains were removed and stored overnight in a $20 \%$ sucrose solution in phosphate buffer at $4^{\circ} \mathrm{C}$. The brains were cut into $60 \mu \mathrm{m}$ serial coronal sections with a freezing micro- tome and treated with tetramethyl benzidine according to the method of Mesulam (1978). The sections, which were counterstained with neutral red, were examined under a light microscope to determine the distribution and number of HRP-labeled cells. The distribution patterns of HRP-labeled cells obtained from the five animals (or the three animals in the case of injection into the ventral and dorsal tendons), which were injected in the same part of the stomach, showed similar tendencies. Quantitative analysis was performed by taking the average of the five animals which were injected with HRP in the same gastric region. The results are shown in Table 1 . In order to study in detail the rostrocaudal distribution of HRPlabeled cells, the total number of labeled cells in each consecutive section was plotted every $120 \mu \mathrm{m}$ in the rostrocaudal direction in which the obex was determined as zero, and shown in the histograms in Fig. 4.

\section{Results}

(a) Cytoarchitectural study

The DMNX of the quail was found to be an elongated cluster of cells in the caudal medulla which lay in close proximity to the central canal and fourth ventricle. The posterior third of the nucleus extended approximately $600 \mu \mathrm{m}$ caudal to the obex and lay dorsolateral to the central canal (CC) (Fig. 2a). The anterior two-thirds of the nucleus lay below the floor of the fourth ventricle (V4), lateral to the midline, and extended approximately $1,200 \mu \mathrm{m}$ rostral to the obex (Fig. 2b-d). The DMNX was bordered ventrally by the hypoglossal motor nucleus (nXII), and dorsally and laterally by the commissural portion of the nucleus of the solitary tract (nTS) (Fig. 2). The nucleus was composed of two cell groups that were distinguished by the size of their neurons and their relative position along the dorsoventral axis of the brainstem in the coronal sections. One group, which consisted of large and medium-sized cells, was named the dorsal subnucleus of the DMNX (Xd). The other was named the ventral subnucleus of the DMNX $(\mathrm{Xv})$ which consisted of a great many small cells (Figs. 2, 3).

Caudal to the obex, there was only the $\mathrm{Xd}$ in the nucleus. The Xd was composed of round and ovoid cells that were approximately $24-32 \mu \mathrm{m}$ in diameter (Fig. 2a).

At the level of the obex, the DMNX was divided into the $\mathrm{Xd}$ and $\mathrm{Xv}$ cell groups. The $\mathrm{Xd}$ was composed of large, polygonal cells as well as medium, ovoid cells. The diameter of these neurons was approximately $24-36 \mu \mathrm{m}$. The $\mathrm{Xv}$ was composed of small, round cells that were approximately $12-20 \mu \mathrm{m}$ in 
Table 1. The number of HRP-labeled cells within the dorsal motor nucleus of the vagus nerve (DMNX) in each injection case, presenting Mean \pm S.D. . Percent shows relative number of labeled cells in each subnucleus of the DMNX to the total number of cells.

\begin{tabular}{|c|c|c|c|c|c|}
\hline \multirow{2}{*}{$\begin{array}{l}\text { Injection } \\
\text { sites }\end{array}$} & \multirow{2}{*}{$\begin{array}{l}\text { Total number } \\
\text { of HRP-labeled } \\
\text { cells in DMNX }\end{array}$} & \multicolumn{2}{|c|}{ Left DMNX } & \multicolumn{2}{|c|}{ Right DMNX } \\
\hline & & $\mathrm{Xd}$ & $\mathrm{Xv}$ & $X d$ & $\mathrm{Xv}$ \\
\hline $\begin{array}{l}V P \\
(n=5)\end{array}$ & $186 \pm 44$ & $\begin{array}{c}80 \pm 28 \\
(43 \%)\end{array}$ & $\begin{array}{l}63 \pm 12 \\
(34 \%)\end{array}$ & $\begin{array}{c}26 \pm 9 \\
(14 \%)\end{array}$ & $\begin{array}{c}17 \pm 15 \\
(9 \%)\end{array}$ \\
\hline $\begin{array}{l}\text { DP } \\
(n=5)\end{array}$ & $253 \pm 77$ & $\begin{array}{c}33 \pm 17 \\
(13 \%)\end{array}$ & $\begin{array}{l}36 \pm 15 \\
(14 \%)\end{array}$ & $\begin{array}{c}100 \pm 34 \\
(40 \%)\end{array}$ & $\begin{array}{l}84 \pm 26 \\
(33 \%)\end{array}$ \\
\hline $\begin{array}{l}\text { CaTk } \\
(n=5)\end{array}$ & $630 \pm 405$ & $\begin{array}{c}207 \pm 153 \\
(33 \%)\end{array}$ & $\begin{array}{l}94 \pm 60 \\
(15 \%)\end{array}$ & $\begin{array}{c}227 \pm 134 \\
(36 \%)\end{array}$ & $\begin{array}{c}102 \pm 63 \\
(16 \%)\end{array}$ \\
\hline $\begin{array}{l}\text { CrTk } \\
(n=5)\end{array}$ & $465 \pm 111$ & $\begin{array}{r}165 \pm 37 \\
(35 \%)\end{array}$ & $\begin{array}{l}77 \pm 21 \\
(17 \%)\end{array}$ & $\begin{array}{r}159 \pm 53 \\
(34 \%)\end{array}$ & $\begin{array}{l}64 \pm 24 \\
(14 \%)\end{array}$ \\
\hline $\begin{array}{l}\text { CrTn } \\
(n=5)\end{array}$ & $892 \pm 481$ & $\begin{array}{c}313 \pm 204 \\
(35 \%)\end{array}$ & $\begin{array}{c}152 \pm 81 \\
(17 \%)\end{array}$ & $\begin{array}{c}276 \pm 151 \\
(31 \%)\end{array}$ & $\begin{array}{c}151 \pm 55 \\
(17 \%)\end{array}$ \\
\hline $\begin{array}{l}\text { CaTn } \\
(n=5)\end{array}$ & $734 \pm 454$ & $\begin{array}{c}248 \pm 150 \\
(34 \%)\end{array}$ & $\begin{array}{c}132 \pm 88 \\
(18 \%)\end{array}$ & $\begin{array}{c}235 \pm 155 \\
(32 \%)\end{array}$ & $\begin{array}{c}119 \pm 63 \\
(16 \%)\end{array}$ \\
\hline $\begin{array}{l}\text { PY } \\
(n=5)\end{array}$ & $961 \pm 76$ & $\begin{array}{c}230 \pm 71 \\
(24 \%)\end{array}$ & $\begin{array}{c}229 \pm 59 \\
(24 \%)\end{array}$ & $\begin{array}{c}261 \pm 58 \\
(27 \%)\end{array}$ & $\begin{array}{c}241 \pm 55 \\
(25 \%)\end{array}$ \\
\hline $\begin{array}{l}\text { VT } \\
(n=3)\end{array}$ & $57 \pm 8$ & $\begin{array}{c}24 \pm 7 \\
(42 \%)\end{array}$ & $\begin{array}{c}5 \pm 7 \\
(9 \%)\end{array}$ & $\begin{array}{c}24 \pm 6 \\
(42 \%)\end{array}$ & $\begin{array}{l}4 \pm 3 \\
(7 \%)\end{array}$ \\
\hline $\begin{array}{l}\text { DT } \\
(n=3)\end{array}$ & $70 \pm 23$ & $\begin{array}{l}32 \pm 9 \\
(46 \%)\end{array}$ & $\begin{array}{l}3 \pm 4 \\
(4 \%)\end{array}$ & $\begin{array}{l}33 \pm 14 \\
(47 \%)\end{array}$ & $\begin{array}{l}2 \pm 3 \\
(3 \%)\end{array}$ \\
\hline
\end{tabular}

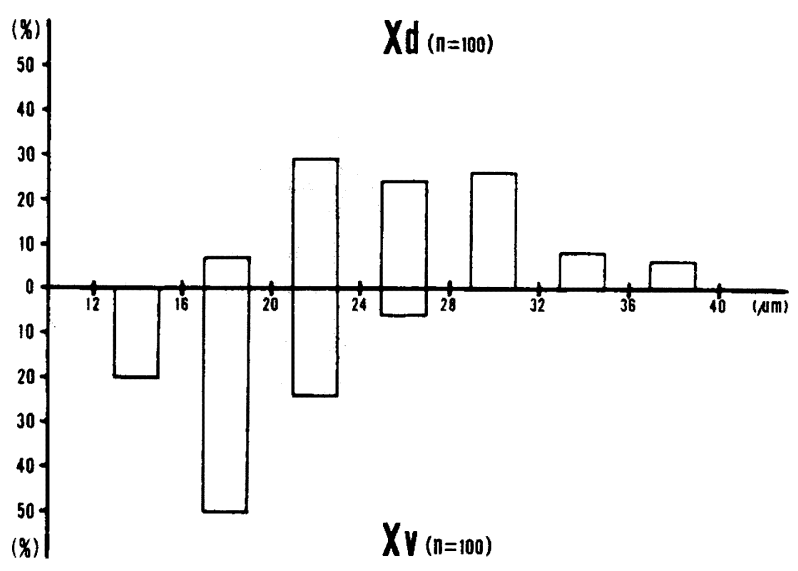

Fig. 3. A histogram of the diameters of vagal neurons in two subnuclei (Xd and Xv) of the quail DMNX. Percentages show the number of neurons in the same-sized cell groups relative to 100 neurons in each subnucleus. The neurons within the Xd predominantly consist of large and mediumsized cells, while the neurons within the $\mathrm{Xv}$ consist of a great many small cells.

diameter (Fig. 2b).

At progressively more rostral levels, between 300 and $600 \mu \mathrm{m}$ anterior to the obex, the cells in the $\mathrm{Xd}$ and the $\mathrm{Xv}$ were round, ovoid neurons that were approximately $20-28 \mu \mathrm{m}$ and $16-24 \mu \mathrm{m}$ in diameter, respectively (Fig. 2c).

At the most rostral levels, between 600 and $1,200 \mu \mathrm{m}$ anterior to the obex, the cells within the $\mathrm{Xd}$ were round and ovoid, and approximately 20$28 \mu \mathrm{m}$ in diameter. The Xv consisted of small, round and ovoid cells that approximately $12-20 \mu \mathrm{m}$ in diameter. The glossopharyngeal motor nucleus (nIX) appeared in the medial area of the rostral DMNX (Fig. 2d).

\section{(b) HRP study}

HRP-labeled cells were consistently identified in the DMNX in all 41 animals. No other brainstem nuclei contained HRP-labeled cells.

(i) Injection into the proventriculus

a) Ventral part

After the injection of HRP into the VP of the proventriculus, HRP-labeled cells were localized in the $\mathrm{Xd}$ within an area ranging from $360 \mu \mathrm{m}$ caudal and $960 \mu \mathrm{m}$ rostral to the obex. Labeled cells of the $\mathrm{Xv}$ were distributed in a region from 360 to $1,200 \mu \mathrm{m}$ rostral to the obex (Fig. 4a). A histogram of the distribution areas of labeled cells along the long axis of the Xd had two peaks. The predominant distribution areas of HRP-labeled cells were approximately from $120 \mu \mathrm{m}$ caudal to $240 \mu \mathrm{m}$ rostral to the obex and $360-720 \mu \mathrm{m}$ rostral to the obex in the Xd (Fig. 4a). Heavily labeled cells were found in the medial area 

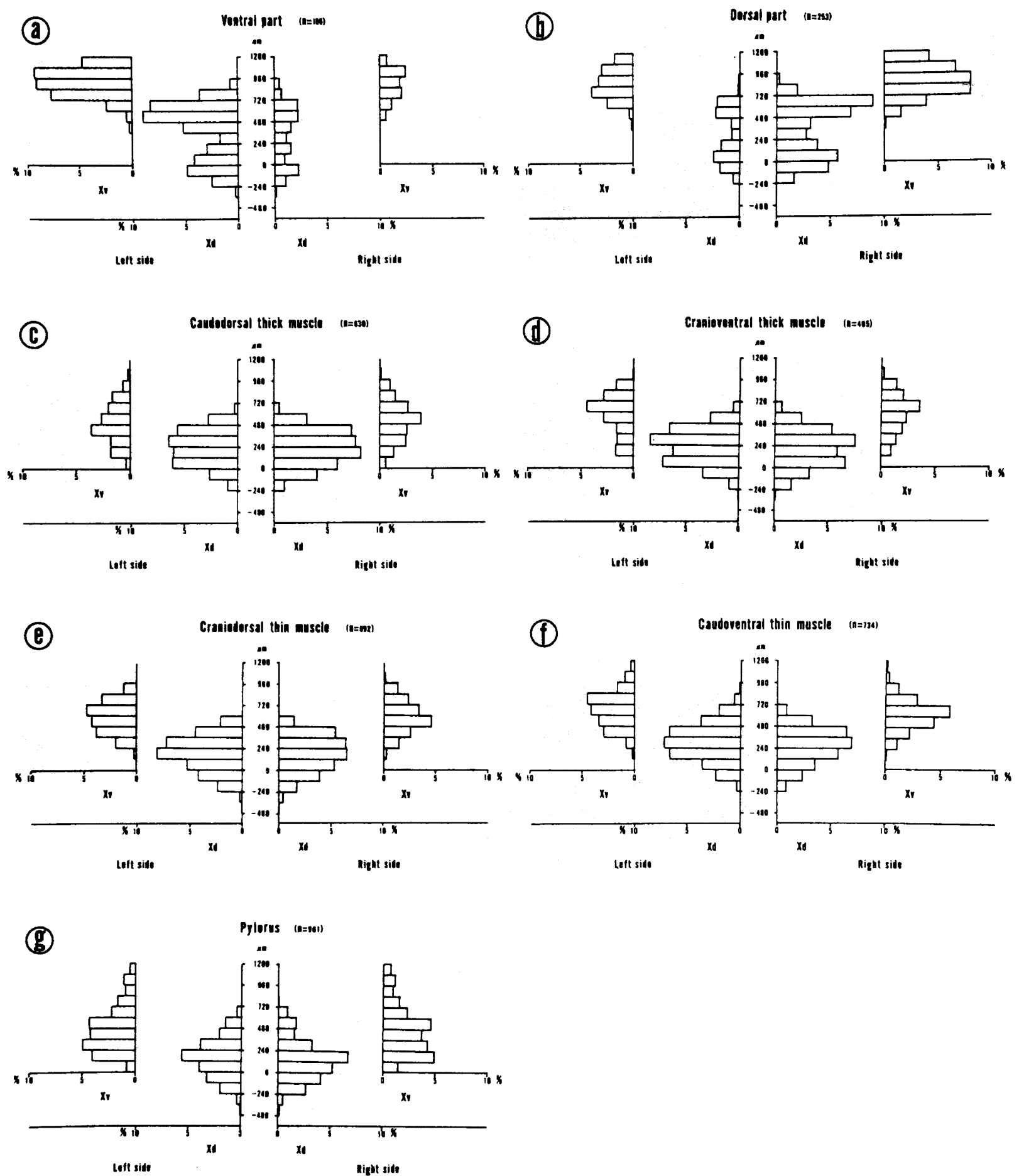

Fig. 4. Each histogram shows the rostrocaudal distribution patterns of HRP-labeled cells in the subnuclear groups Xd and Xv, after the injection of HRP into seven different gastric regions: ventral (a) and dorsal (b) parts of the proventriculus, caudodorsal (c) and cranioventral (d) thick muscles, craniodorsal (e) and caudoventral (f) thin muscles, and pylorus (g) of the gizzard. The vertical axis of each histogram indicates the rostrocaudal location in the DMNX. Zero is determined as the obex. Minus and plus indicate directions caudal and rostral to the obex, respectively. The horizontal axis shows the average percentage of HRPlabeled cells out of the total average number of cells obtained from five birds which were injected in the same part of the stomach. 
of the left DMNX (Fig. 5a). The predominantly labeled area in the $\mathrm{Xv}$ was approximately 720$1,080 \mu \mathrm{m}$ rostral to the obex (Fig. 4a).

The distribution of the population of HRP-labeled cells in the DMNX was $77 \%$ on the left and $23 \%$ on the right sides (Table 1, Fig. 4a), indicating that the left vagus nerve projected predominantly to the VP. The distribution of HRP-labeled cells in the Xd and the $\mathrm{Xv}$ was $57 \%$ and $43 \%$, respectively (Table 1 , Fig. 4a).

\section{b) Dorsal part}

After the injection of HRP into the DP of the proventriculus, HRP-labeled cells were found in the Xd from $240 \mu \mathrm{m}$ caudal to $960 \mu \mathrm{m}$ rostral to the obex. Labeled neurons in the Xv were located in a range $360-1,200 \mu \mathrm{m}$ rostral to the obex (Fig. $4 \mathrm{~b}$ ). A histogram of the distribution areas of labeled cells along the long axis of the $\mathrm{Xd}$ had two peaks. The primary distribution areas of HRP-labeled cells were in the $\mathrm{Xd}$, approximately from $120 \mu \mathrm{m}$ caudal to $240 \mu \mathrm{m}$ rostral to the obex and $360-720 \mu \mathrm{m}$ rostral to the obex (Fig. 4b). Heavily labeled cells were found in the medial area of the right DMNX (Fig. 5b). The primary distribution area in the $\mathrm{Xv}$ was approximately $720-1,080 \mu \mathrm{m}$ rostral to the obex (Fig. $4 \mathrm{~b}$ ).

The distribution of HRP-labeled cells was found to be distributed with $73 \%$ on the right and $27 \%$ on the left sides (Table 1, Fig. 4b). In contrast to the findings with VP injection case, the right vagus nerve projected mainly to the DP. The distribution of HRP-labeled cells in the $\mathrm{Xd}$ and the $\mathrm{Xv}$ was $53 \%$ and $47 \%$, respectively (Table 1 , Fig. $4 b$ ).

(ii) Injection into the gizzard

a) Caudodorsal thick muscle

After the injection of HRP into the CaTk of the gizzard, HRP-labeled cells were localized in the Xd, approximately from $240 \mu \mathrm{m}$ caudal to $720 \mu \mathrm{m}$ rostral to the obex, and in the Xv approximately between the level of the obex and $1,080 \mu \mathrm{m}$ rostral to the obex (Fig. 4c). The predominant distribution area of HRPlabeled cells was approximately between the level of the obex and $480 \mu \mathrm{m}$ rostral to the obex in the Xd, and approximately $360-720 \mu \mathrm{m}$ rostral to the obex in the Xv (Fig. 4c, Fig. 6a).

The lateral distribution of HRP-labeled cells observed in the DMNX was $48 \%$ on the left and $52 \%$ on the right sides (Table 1, Fig. 4c). There was very little difference in the number of neurons between the left and right DMNX after the injection into the CaTk of the gizzard (Fig. 6a). The distribution of labeled cells in the $\mathrm{Xd}$ and the $\mathrm{Xv}$ was $69 \%$ and $31 \%$, respectively (Table 1, Fig. $4 \mathrm{c}$ ). b) Cranioventral thick muscle

After the injection of HRP into the CrTk of the gizzard, HRP-labeled cells were localized in the $\mathrm{Xd}$, approximately from $360 \mu \mathrm{m}$ caudal to and $720 \mu \mathrm{m}$ rostral to the obex, and in the $\mathrm{Xv}$ approximately $120-1,080 \mu \mathrm{m}$ rostral to the obex (Fig. 4d). The primary distribution area of labeled cells was approximately between the level of the obex and $360 \mu \mathrm{m}$ rostral to the obex in the $\mathrm{Xd}$, and approximately $480-840 \mu \mathrm{m}$ rostral to the obex in the Xv (Fig. 4d). Distribution patterns of labeled cells in the $\mathrm{Xd}$ and the $\mathrm{Xv}$ were similar to those after the injection into the CaTk.

HRP-labeled cells observed in the DMNX were distributed with $52 \%$ on the left and $48 \%$ on the right sides (Table 1, Fig. 4d). The distribution of labeled cells in the $\mathrm{Xd}$ and the $\mathrm{Xv}$ were $69 \%$ and $31 \%$, respectively (Table 1, Fig. 4d).

c) Craniodorsal thin muscle

After the injection of HRP into the CrTn of the gizzard, labeled cells were localized in the $\mathrm{Xd}$, approximately from $360 \mu \mathrm{m}$ caudal to $600 \mu \mathrm{m}$ rostral to the obex, and in the Xv approximately $120-1,080 \mu \mathrm{m}$ rostral to the obex (Fig. 4e). The primary distribution area of HRP-labeled cells was approximately between the level of the obex and $360 \mu \mathrm{m}$ rostral to the obex in the $\mathrm{Xd}$, and approximately $360-720 \mu \mathrm{m}$ rostral to the obex in the Xv (Fig. 4e, Fig. 6b).

HRP-labeled cells observed in the DMNX were distributed as $52 \%$ on the left and $48 \%$ on the right sides (Table 1, Fig. 4e). The distribution of labeled cells in the $\mathrm{Xd}$ and the $\mathrm{Xv}$ was $66 \%$ and $34 \%$, respectively (Table 1, Fig. 4e).

d) Caudoventral thin muscle

After the injection of HRP into the CaTn of the gizzard, labeled cells were localized in the $\mathrm{Xd}$, approximately from $240 \mu \mathrm{m}$ caudal to $960 \mu \mathrm{m}$ rostral to the obex, and in the Xv approximately $120-1,200 \mu \mathrm{m}$ rostral to the obex (Fig. 4f). The predominant distribution area of labeled cells was approximately 120 $480 \mu \mathrm{m}$ rostral to the obex in the $\mathrm{Xd}$, and observed in approximately $480-840 \mu \mathrm{m}$ rostral to the obex in the Xv (Fig. 4f). Distribution patterns of labeled cells in the $\mathrm{Xd}$ and the $\mathrm{Xv}$ were similar to those after the injection into the CrTn.

HRP-labeled cells found in the DMNX were distributed $52 \%$ on the left and $48 \%$ on the right sides (Table 1, Fig. 4f). The distribution of labeled cells in the $\mathrm{Xd}$ and the $\mathrm{Xv}$ was $66 \%$ and $34 \%$, respectively (Table 1, Fig. 4f).

\section{e) Pylorus}

After the injection of HRP into the PY of the gizzard, labeled cells were localized in the $\mathrm{Xd}$, ap- 
proximately from $480 \mu \mathrm{m}$ caudal to $720 \mu \mathrm{m}$ rostral to the obex, and in the Xv approximately between the level of the obex and $1,200 \mu \mathrm{m}$ rostral to the obex (Fig. $4 \mathrm{~g}$ ). The primary distribution area of labeled cells was approximately from $120 \mu \mathrm{m}$ caudal to $360 \mu \mathrm{m}$ rostral to the obex in the $\mathrm{Xd}$, and observed in approximately $120-600 \mu \mathrm{m}$ rostral to the obex in the Xv (Fig. 4g, Fig. 6c).

HRP-labeled cells observed in the DMNX were distributed as $48 \%$ on the left and $52 \%$ on the right sides (Table 1, Fig. 4g). The distribution of labeled cells in the $\mathrm{Xd}$ and the $\mathrm{Xv}$ was $51 \%$ and $49 \%$, respectively (Table 1 , Fig. $4 \mathrm{~g}$ ).

The above results show that there was little difference in the population of labeled neurons on the left and right sides in the $\mathrm{Xd}$ and the $\mathrm{Xv}$ after the injection of HRP into the gizzard. However, comparison of the number of HRP-labeled neurons in the two regions revealed rates of $70 \%$ and $30 \%$ in the $\mathrm{Xd}$ and $\mathrm{Xv}$, respectively, except for the case of $P Y$ injection.

\section{f) Ventral tendon and dorsal tendon}

The distribution pattern of HRP-labeled cells following the injection into the ventral and dorsal parts of the proventriculus showed pronounced lateralization. HRP was injected into the VT and DT in order to identify the phenomenon, in the gizzard, which was seen after injection into the proventriculus.

Labeled cells were localized in the Xd, approximately from $240 \mu \mathrm{m}$ caudal to $360 \mu \mathrm{m}$ rostral to the obex, while a very few labeled cells were observed in the $\mathrm{Xv}$, approximately $360-840 \mu \mathrm{m}$ rostral to the obex (not illustrated). Vagal neurons projecting to the VT and DT were concentrated in a more limited area than the ones projecting to other regions of the gizzard.

There was little difference in the number of neurons between the left and right DMNX after VT and DT injection (Table 1). Moreover, the distribution of labeled cells in the $\mathrm{Xd}$ and $\mathrm{Xv}$ was in a ratio of approximately nine to one (Table 1 ).

\section{Discussion}

\section{(a) Cytoarchitectural study}

Cytoarchitectural analysis in the present study indicated that the DMNX is composed of two subnuclei, the dorsal subnucleus $(\mathrm{Xd})$ and the ventral subnucleus $(\mathrm{Xv})$ of the DMNX. The location of Xd and $\mathrm{Xv}$ suggests that they correspond respectively to the dorsal motor nucleus of the vagus nerve (nX) and the nucleus intercalatus (nIC), which has been described in the pigeon (Karten \& Hodos, 1967). On the other hand, the nIC was termed the ventral parvicellular subnucleus of $\mathrm{nX}(\mathrm{Xv})$ in the pigeon by Berk \& Finkelstein (1983). Furthermore, our findings in the HRP study indicated that neurons of the Xv were retrogradely labeled following the injection of HRP into the stomach. Therefore, from the present study we considered that the ventral area of the DMNX containing small cells was a part of the DMNX and named it the $\mathrm{Xv}$, while the dorsal area of the DMNX containing large and medium-sized cells was named the $\mathrm{Xd}$.

The cytoarchitecture of the avian DMNX was previously described by Sanders (1929), Watanabe (1968), Cohen et al. (1970), and Katz \& Karten (1983). Watanabe (1968) subdivided the DMNX of the chicken into three regions in the rostrocaudal direction: the caudal and rostral regions of small cells and the middle region of large and mediumsized cells. Our results are consistent with Watanabe's (1968) findings that the dorsal area of the middle DMNX consisted of large and medium-sized cells, and the ventral area of the rostral DMNX contained many small cells.

Cohen et al. (1970), on the other hand, reported that the DMNX of the pigeon was composed of three subnuclei, termed a dorsal area containing predominantly large cells as subnucleus $\mathrm{A}$, an intermediate area containing medium-sized cells as subnucleus $B$ and a ventral area containing small cells as subnucleus $\mathrm{C}$, which were distinguished by the morphology of the neurons and their relative positions along the dorsoventral axis. Moreover, those authors found that small cells constituting the subnucleus $\mathrm{C}$ disappeared in the caudal DMNX. Hence, the subnucleus $\mathrm{C}$ corresponded to the $\mathrm{Xv}$ in our results. The subnucleus $\mathrm{A}$ and $\mathrm{B}$ are thought to correspond to the $\mathrm{Xd}$ of the present study, in which large and mediumsized cells mingled.

\section{(b) HRP study}

(i) Injection into the proventriculus

In the present study, HRP-labeled vagal preganglionic neurons innervating the ventral and dorsal parts of the proventriculus were found mainly in the left and right sides of the DMNX with pronounced lateralization. These results correspond to those in the rat (Takayama et al., 1982; Okumura \& Namiki, 1990) and the cat (Pagani et al., 1983). The phenomenon of lateralized topographic projections in mammals has been attributed to the fact that a $90^{\circ}$ clockwise rotation of the stomach occurs during development, and subsequently orients the left aspect of the stomach wall anteriorly and the right aspect of the stomach wall posteriorly. However, it is not known whether stomach rotation occurs in birds in mammals. The present results may be related to the ramification pattern of the vagus nerve to the stomach, 
which may differ between birds and mammals. The underlying cause of the present results is thought to be as follows.

Watanabe (1960) observed that the bilateral vagal trunks which ran up the esophagus to the proximal end of the proventriculus and separated into the main trunk and branches. After ramification at the level of the proximal proventriculus, the branches were distributed to the ventral proventriculus whereas the main trunks passed through the surface of the dorsal proventriculus and anastomozed with the other side trunks. However, this anastomosis was incomplete and merely resulted in exchange of nerve fibers with each other through the anastomotic branches. A number of ramifications which arose from the bilateral vagal trunks and their anastomotic branches were sent to the dorsal surface of the proventriculus. In the present study, the left vagus nerve projected mainly to the ventral part of the proventriculus, while the right vagus nerve also projected to this part. This findings indicates that the bilateral vagus nerve projected to the ventral part as described by Watanabe (1960), suggesting that the ratio of the left and right vagus nerve projections to this part is three-to-one. On the other hand, the right vagus nerve projection to the dorsal part of the proventriculus was stronger than that of the left vagus nerve in the present study. This findings indicates that the bilateral vagal trunks and their anastomotic branches projected predominantly to the dorsal part of the proventriculus. Therefore, the right and left vagal projections to the dorsal proventriculus in the Japanese quail are proportionally distributed threeto-one to the right in contrast to the case with ventral part injection.

Though the present observation of a number of HRP-labeled cells in the dorsal subnucleus (Xd) of the middle DMNX following the injection into the proventriculus is consistent with the observation in the pigeon by Katz \& Karten (1985), the other distribution patterns of labeled cells differed from them in some respects: our findings indicated that heavily vagal preganglionic neurons projecting to this organ were localized in the medial area of the middle Xd. Katz \& Karten (1985), however, showed that there were a few proventricular motoneurons within the posterior ventral magnocellular subnucleus (pVM) located in the medial area of the middle DMNX. On the other hand, Watanabe (1968) reported the topographic localization of gastric motoneurons within the medial area of the middle and rostral regions of the nucleus in the chicken. His results might be related to ours. Furthermore, a number of vagal neurons innervating this organ were also observed in the ventral subnucleus $(\mathrm{Xv})$ of the rostral DMNX in the present study. Katz \& Karten
(1985) indicated that there were only a few vagal neurons in the anterior ventral parvicellular subnucleus (aVP) for the proventriculus, and these neurons within the posterior ventral parvicellular subnucleus (pVP) as well as the aVP projected mainly to the caudal regions of this organ; i.e., the gizzard, pancreas, and other posterior abdominal organs. Such differences between their results and ours may be due to methodological differences. They applied HRP to the end of the cut vagus nerve, while we injected a small amount of HRP into the target sites directly.

The rostrocaudal distribution patterns of HRPlabeled cells in the Xd were the same on the left and right sides with two peaks after the dorsal and ventral injections into the proventriculus. Labeled cells in the $\mathrm{Xv}$ were also distributed symmetrically as seen in the $\mathrm{Xd}$. Therefore, our findings suggest that there is topographic localization in the distribution patterns of the vagal preganglionic neurons innervating the ventral and dorsal parts of the proventriculus.

\section{(ii) Injection into the gizzard}

The vagal preganglionic neurons innervating each muscle constituting the wall of the gizzard were bilaterally found in the DMNX. Furthermore, when we injected HRP into the ventral and dorsal tendons of the gizzard, HRP-labeled cells were observed in the bilateral DMNX and the populations of labeled cells of the left and right vagus nerve which projected to the gizzard were approximately equal. This result supported the finding of Watanabe (1968). He reported that the vagus nerve descended on the dorsolateral surface of the proventriculus with anastomosis of the left and right nerve at the level of the rostral region of the proventriculus. The anastomotic nerve then separated again into two branches at the caudal one-third level of this organ, and the right and left vagus nerve entered mainly into the ventral and dorsal surfaces of the gizzard, respectively. However, Watanabe (1968) from results of the degeneration method in the chicken, suggested that the left and right nerve fibers might mix and cross at the anastomotic level of the proventriculus since chromatolytic cells were observed in the DMNX in a similar ratio to that found after unilateral vagotomy of this organ.

The distribution patterns of vagal preganglionic neurons innervating the gizzard alone have not been reported by previous authors (Watanabe, 1968; Cohen et al., 1970; Katz \& Karten, 1985). The latter authors described the pattern in the caudal abdominal organs, which included the gizzard, pancreas. and other posterior organs. Our findings that a number of the HRP-labeled cells were observed in the middle Xd and the caudal two-thirds of the $\mathrm{Xv}$ following the injection into the gizzard nearly correspond with the 
report of Katz \& Karten (1985). However, our results differed from theirs in that there were few motoneurons projecting to the caudal abdominal organs involving the gizzard within the posterior intermediate mediocellular subnucleus of the DMNX, which corresponded to the intermediate area of the middle DMNX in the present study.

In the present study, the distribution patterns of vagal preganglionic neurons innervating the caudodorsal and cranioventral thick muscles or the craniodorsal and caudoventral thin muscles almost corresponded with other as seen in Fig. 4. Therefore, it could be considered that a single vagal neuron within the DMNX projected to some muscles of the gizzard by giving rise to collateral branches. In order to verify this hypothesis, it is necessary that several kinds of retrograde fluorescent tracers be simultaneously injected into some muscles of the gizzard.

\section{(iii) General findings}

We found that a number of labeled cells were localized in the middle and rostral regions of the DMNX after the injection of HRP into the proventriculus and the gizzard. Watanabe (1968) reported that the ventral and medial areas of the rostral and middle regions of the DMNX were concerned with the innervation of the stomach in the chicken. Cohen et al. (1970) showed that the rostral two-thirds of the DMNX innervated the abdominal organ in the pigeon. Furthermore, Katz \& Karten (1985) also demonstrated that the vagal preganglionic neurons projecting to the stomach in the pigeon were localized in the central portion of the DMNX at the level of and rostral to the obex. The present findings were generally consistent with those of previous authors. However, there were few vagal neurons innervating the stomach in the caudal and the most anterior Xd in the present study. Katz \& Karten (1985) reported that a considerable number of vagal neurons within the caudal and the anterior DMNX, except for the ventral parvicellular subnuclei ( $\mathrm{pVP}$ and aVP), which corresponded to the $\mathrm{Xd}$ in the present study, projected to the cervical and the thoracic esophagus. Therefore, it could be considered that rostral and caudal Xd innervate the esophagus in the quail.

In the present study, the topographical distribution of HRP-labeled cells along the rostrocaudal axis of the DMNX reflected the several areas of the avian stomach. Thus, the rostro-to-caudal distribution sequence of the vagal preganglionic neurons in both the Xd and the Xv reflected the following rostro-tocaudal order of the target organs: the proventriculus, the thick and the thin muscles of the gizzard, and the pylorus of the gizzard, corresponding to the rostroto-caudal order of these organs in the periphery as seen in Figs. 4 \& 7.
Finally, the present study demonstrated that the site-related differences in gastric motility may also correspond to the neuroanatomical differences in the gastric innervation of the DMNX.

\section{Acknowledgments}

The authors are grateful to Mr. Akio Ebihara in Ebihara's quail farm for supplying us with quails. We wish to thank Mr. Nobuhisa Fujikake for his technical assistance.

\section{References}

1) Bennet $T$. The peripheral and autonomic nervous systems. In: Avian Biology (Farner, DS; King, JR. and Parkes, KC. eds) 1-46, Academic press, New York. 1974.

2) Berk ML. and Finkelstein, JA. Long descending projections of the hypothalamus in the pigeon. Columba livia. J. Comp. Neurol. 1983; 220:127-136.

3) Chaplin SB and Duke GE. Effect of denervation on initiation and coordination of gastroduodenal motility in turkeys. Am. J. Physiol. 1983; 255:1-6.

4) Chaplin SB and Duke GE. Effect of denervation of the myenteric plexus on gastroduodenal motility in turkeys. Am. J. Physiol. 1990; 259:481-489.

5) Cohen DH, Schnall AM, Macdonald RL and Pitts LH Medullary cells of origin of vagal cardioinhibitory fibers in the pigeon. I. Anatomical studies of peripheral vagus nerve and the dorsal motor nucleus. J. Comp. Neurol. 1970; 140: 299-320.

6) Duke GE. Gastrointestinal motility and its regulation. Poultry Sci. 1982; 61:1245-1256.

7) Duke GE. Alimental canal: Anatomy, regulation of feeding, and motility. In Avian Physiology (Sturkie, PD. ed) 269-285, Springer-Verlag, New York, Berlin, Heidelberg, Tokyo, 1986

8) Duke GE. Recent studies on regulation of gastric motility in turkeys. Poultry Sci. 1992; 71:1-8.

9) Duke GE and Kostuch TE. The use of strain-gauge transducers to study gastrointestinal motility in turkeys. Poultry Sci. 1975; 54:1472-1478.

10) Dziuk HE and Duke GE. Cineradiographic studies of gastric motility in turkeys. Am. J. Physiol. 1972; 222: 159-166.

11) Karten HJ and Hodos W. A stereotaxic atlas of the brain of the pigeon (Columba livia). Johns Hopkins University Press, Baltimore, 1967.

12) Katz DM and Karten HJ. Subnuclear organization of the dorsal motor nucleus of the vagus nerve in the pigeon, Columba livia. J. Comp. Neurol. 1983; 217:31-46.

13) Katz DM and Karten HJ. Topographic representation of visceral target organs within the dorsal motor nucleus of the vagus nerve of the pigeon. Columba livia. J. Comp. Neurol. $1985 ; 242: 397-414$

14) Mesulam MM. Tetramethyl benzidine for horseradish peroxidase neurohistochemistry: a non-carcinogenic blue reaction product with superior sensitivity for visualizing neural afferents and efferents. J. Histochem. Cytochem. 1978; 26:106-117

15) Okumura $T$ and Namiki $M$. Vagal motor neurons innervating the stomach are site-specifically organized in the 
dorsal motor nucleus of the vagus nerve in rats. J. Auton. Nerv. Syst. 1990; 29:157-162.

16) Pagani FD, Norman WP and Gillis RA. Medullary parasympathetic projections innervate specific sites in the feline stomach. Gastroenterology 1983; 95:277-288.

17) Sanders EB. A consideration of certain bulbar, midbrain, and cerebellar centers and fiber tracts in birds. J. Comp. Neurol. 1929; 49:155-222.

18) Takayama $K$, Ishikawa $N$ and Miura $M$. Sites of origin and termination of gastric vagus preganglionic neurons: an HRP study in the rat. J. Auton. Nerv. Syst. 1982; 6: 211-223.

19) Watanabe T. Comparative and topographical anatomy of the fowl. VII. On the peripheral course of the vagus nerve in the fowl. Jpn. J. Vet. Sci. 1960; 22:145-154.

20) Watanabe T. A study of retrograde degeneration in the vagal nuclei of the fowl. Jpn. J. Vet. Sci., 1968; 30:331-340.
CaTk

CaTn

$\mathrm{CC}$

CrTk

CrTn

D

DMNX

DP

DT

G

nTS

nIX

nXII

$P$

PY

VP

VT

V4

$X d$

$\mathrm{XV}$

\section{Abbreviations}

caudodorsal thick muscle

caudoventral thin muscle central canal

cranioventral thick muscle

craniodorsal thin muscle

duodenum

dorsal motor nucleus of the vagus nerve

dorsal part of the proventriculus

dorsal tendon

gizzard

nucleus tractus solitarius

nucleus of the glosspharyngeal nerve

nucleus of the hypoglossal nerve

proventriculus

pylorus

ventral part of the proventriculus

ventral tendon

fourth ventricle

dorsal part of the DMNX

ventral part of the DMNX 
Plate I
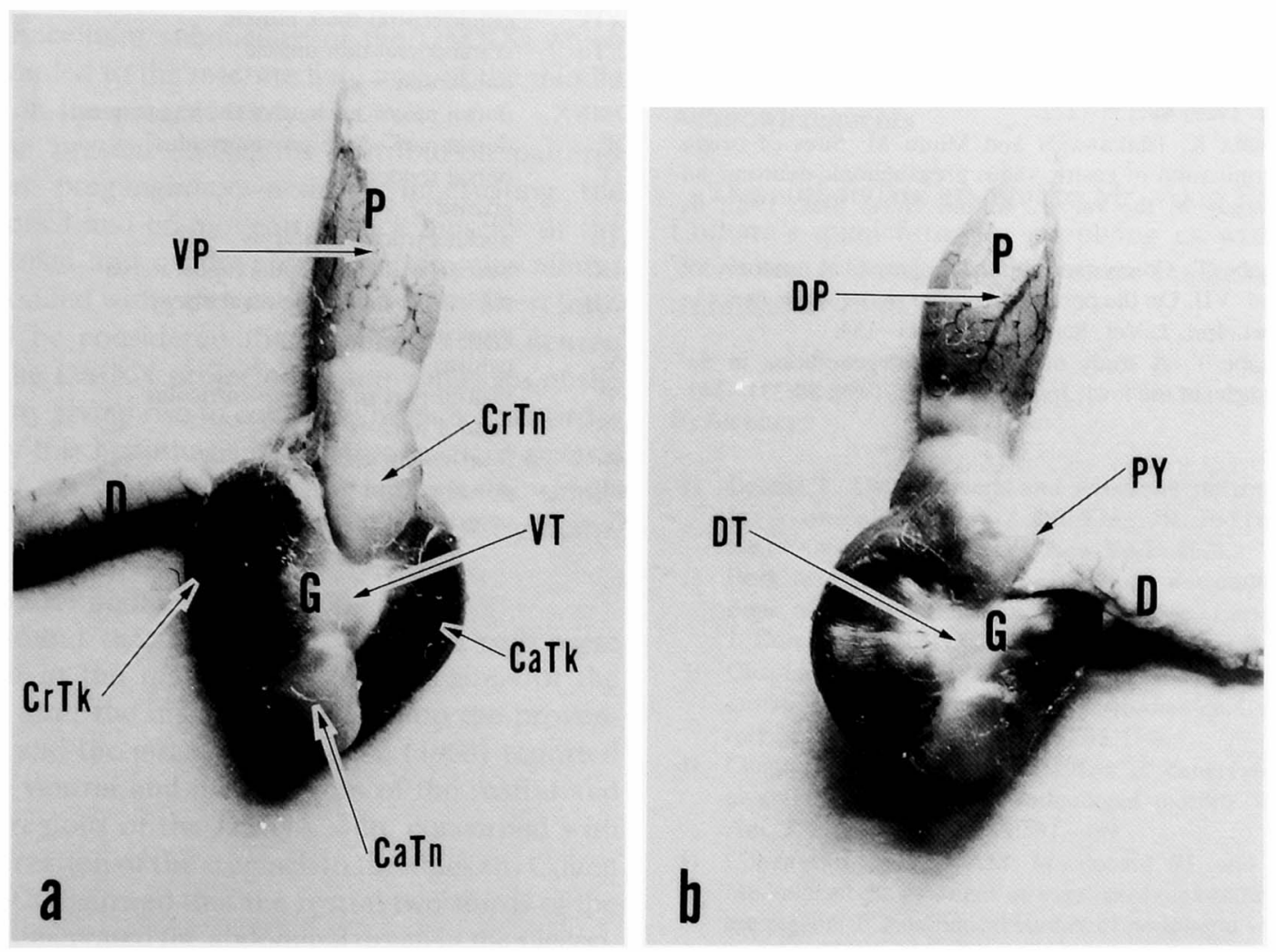

\section{Explanation of Figures}

\section{Plate I}

Fig. 1. Photographs showing the injection sites of the ventral (a) and dorsal (b) surfaces of the stomach in the Japanese quail. 

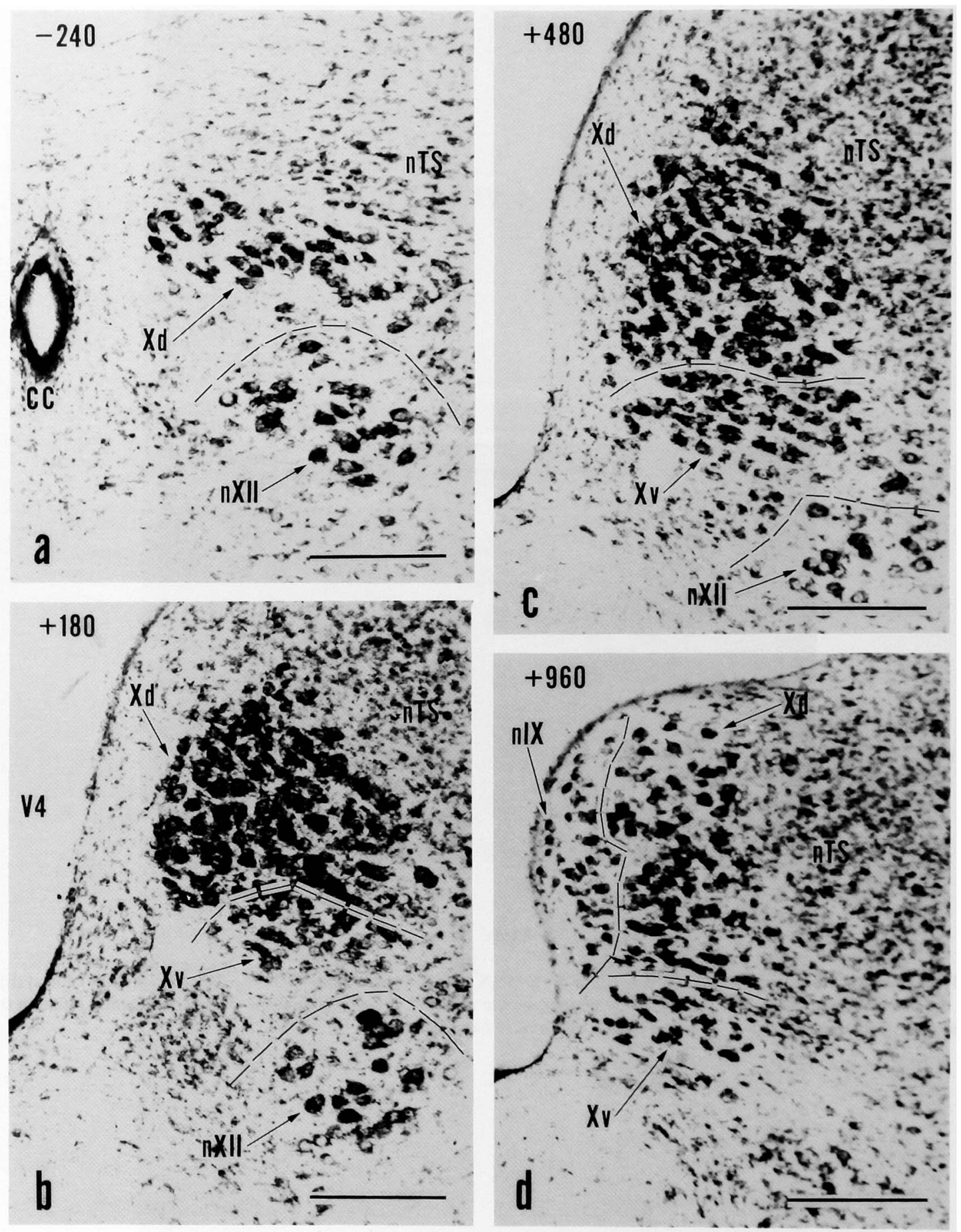

\section{Plate II}

Fig. 2. Photomicrographs (a), (b), (c) and (d) show Nissl-stained coronal sections of the right DMNX, representing each subnucleus. Numbers in each photomicrograph show the distance (unit: $\mu \mathrm{m}$ ) from the level of the obex. Minus and plus indicate caudal and rostral directions to the obex, respectively. Calibration bars: $200 \mu \mathrm{m}$. 
Plate III
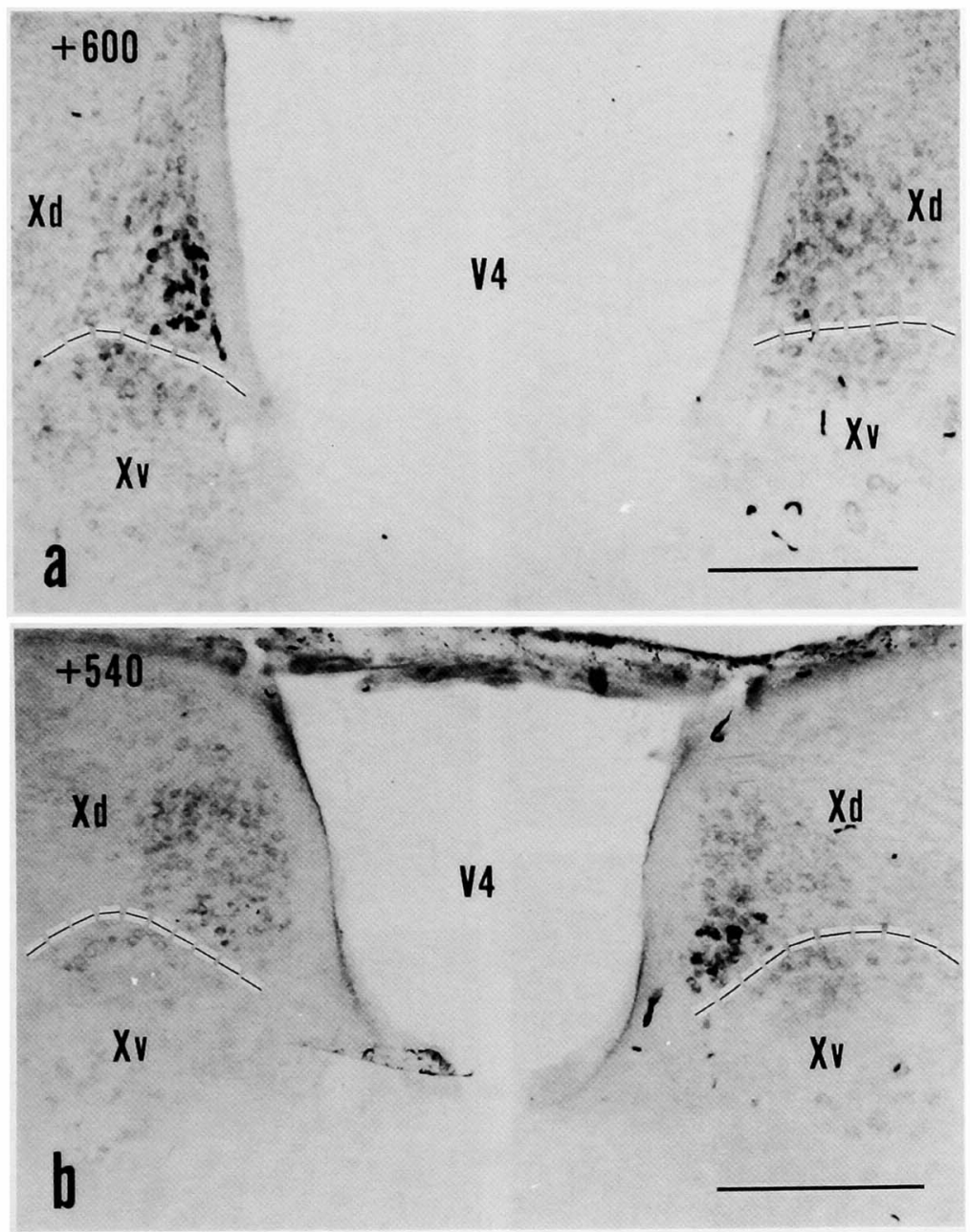

Plate III

Fig. 5. Photomicrographs showing HRP-labeled cells in the DMNX after the injection of HRP into the ventral (a) and dorsal (b) parts of the proventriculus. Numbers in each photomicrograph are as in Fig. 2. Labeled neurons are predominantly found in the left and right medial areas of the Xd, respectively. Calibration bars: $300 \mu \mathrm{m}$. 
Plate IV

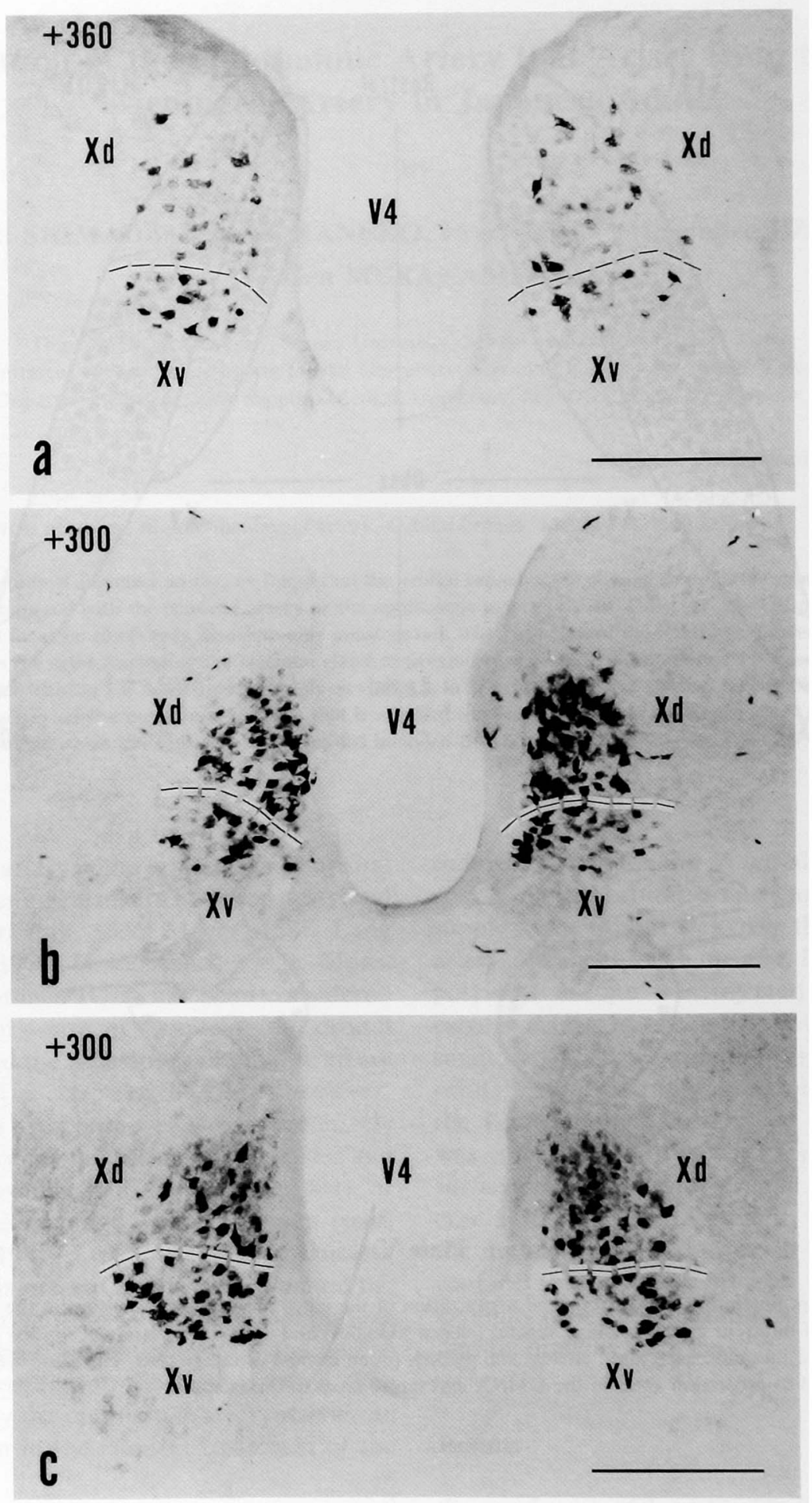

Plate IV

Fig. 6. Photomicrographs showing HRP-labeled cells in the DMNX after the injection of HRP into the CaTk (a), the CrTk (b) and the pylorus (c) of the gizzard. Numbers in each photomicrograph are as in Fig. 2. Heavily labeled ncurons are found in the middle DMNX. The distribution patterns of HRP-labeled cells following the injection of HRP into each muscle of the gizzard show less than topographic organization after injection HRP into the proventriculus and no lateral predominance. Calibration bars: $300 \mu \mathrm{m}$. 
Plate V

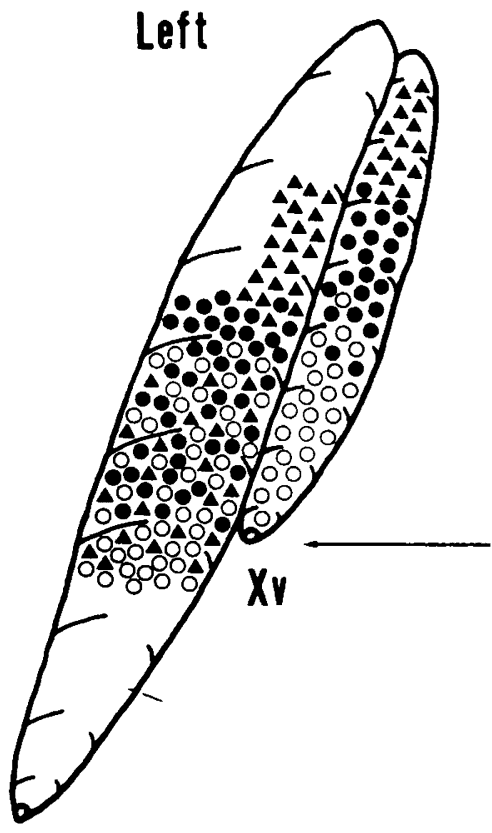

$X_{d}$

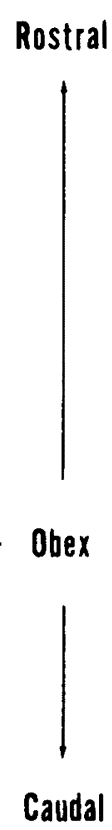

Caudal

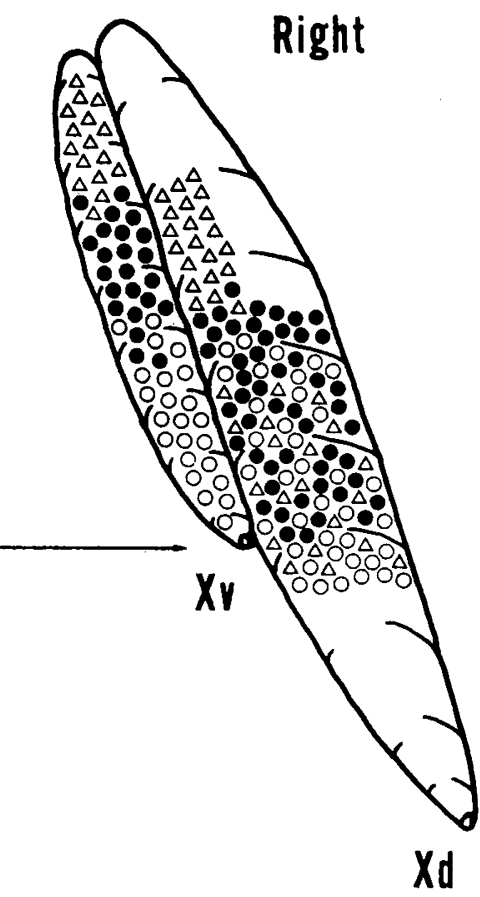

Dorsal

Plate V

Fig. 7. Summary diagram illustrating the rostrocaudal organization of the vagal preganglionic neurons in the DMNX (Xd and Xv) which innervate the different gastric regions: ventral (closed triangles) and dorsal (open triangles) parts of the proventriculus, the pair of thick and thin muscles (closed circles) and pylorus (open circles) of the gizzard. The same symbols for DMNX and stomach correspond to projection areas in the DMNX and target areas in the stomach. 